\title{
Aborto: 20 anos de pesquisas no Brasil
}

\author{
Abortion: 20 years of Brazilian research
}

\section{Universidade de Brasília, Brasília, Brasil. \\ 2 Universidade do Estado do Rio de Janeiro, Rio de Janeiro, Brasil. \\ Correspondência D. Diniz \\ Universidade de Brasília. C. P. 8011 , Brasília, DF 70673-970, Brasil. anis@anis.org.br}

\author{
Debora Diniz 1 \\ Marilena Corrêa 2 \\ Flávia Squinca 1 \\ Kátia Soares Braga 1
}

Estudar uma prática ilegal é um desafio para qualquer equipe de pesquisa. Não há garantias legais de segredo ou sigilo para os dados coletados nas pesquisas acadêmicas no Brasil. Em uma pesquisa sobre crimes, a promessa de confidencialidade dos dados é um voto de confiança dado ao pesquisador pelos participantes em nome do conhecimento científico. Esse é o cenário que marcou os vinte últimos anos de pesquisa sobre aborto no Brasil (1987-2007). O projeto de pesquisa Aborto e Saúde Pública foi conduzido pela Universidade de Brasília e pela Universidade do Estado do Rio de Janeiro e teve o objetivo de sistematizar vinte anos de publicações sobre o tema do aborto no Brasil. Foram recuperadas 2.109 fontes em Língua Portuguesa, publicadas por autores, periódicos e editoras nacionais ou estrangeiros de todas as áreas do conhecimento.

Este artigo tem o objetivo de apresentar as principais características do campo de pesquisa sobre aborto no Brasil. Foram pesquisadas 88 bases bibliográficas de dados de acesso público e a recuperação das fontes foi realizada por intermédio de um vocabulário com 59 descritores. Dentre as fontes de informação e referências bibliográficas, foram localizados livros e capítulos de livros; periódicos e artigos de periódicos; resumos e trabalhos apresentados em eventos científicos; teses, dissertações e monografias de especializações produzidas nas instituições de Ensino Superior em todo o país e notas técnicas de órgãos públicos. 
As fontes foram organizadas com base em uma dupla categorização: "estudos com base empírica” (398 fontes) e "estudos sem base empírica” (1.711 fontes). Entendeu-se como "estudo de base empírica" toda fonte que em seu resumo e/ou título indicasse que houve pesquisa com dados primários ou secundários. Foi cadastrada como "estudo sem base empírica" toda fonte cujo resumo e/ou título indicasse que se tratava de um documento argumentativo sem a utilização de dados primários ou secundários. Para a avaliação dos estudos com base empírica e dos estudos sem base empírica, foram utilizados dois questionários. Dois pesquisadores participaram da fase de avaliação das fontes, sendo um responsável pela avaliação e o outro pela checagem. Em caso de discordância, um terceiro pesquisador participou da avaliação. Os questionários foram preenchidos e digitados no programa Access (Microsoft Corp., Estados Unidos). Posteriormente, foram exportados para o programa Excel (Microsoft Corp., Estados Unidos). Os dados foram analisados no Statistical Analysis System (SAS Inst., Cary, Estados Unidos). A análise e síntese das fontes foram realizadas por três pesquisadores.

\section{Quem pesquisa?}

O campo de estudos sobre aborto é dominado por mulheres pesquisadoras, sediadas em universidades públicas e organizações não governamentais da Região Sudeste, com formação em Ciências da Saúde. Os meios de comunicação científica prioritários do campo são os periódicos científicos, com $47 \%$ do total de fontes recuperadas, os livros, com $18 \%$, e as teses acadêmicas, com $14 \%$. O tema do aborto se manteve ativo na comunicação científica durante os vinte anos em que se produziram as fontes recuperadas, mas houve um crescimento de $50 \%$ no número de publicações em 2004 e 2005, retornando ao cenário de início da década em 2006. Uma análise do que foi publicado nesses dois anos mostra um aumento na quantidade de estudos no campo jurídico, em particular sobre o aborto por anomalia fetal.

Uma característica do campo de pesquisas sobre aborto é a hegemonia de estudos sem base empírica. Para cada estudo com base empírica, há pelo menos cinco sem base empírica, ou seja, parte considerável das fontes é de análises de argumentos e/ou teses teóricas, sem a utilização de dados primários ou secundários. A grande maioria dos estudos de base empírica é da área da Saúde Pública, ao passo que os estudos sem base empírica se concentram nas áreas do Di- reito, da Teologia e da Filosofia. Nos estudos sem base empírica, os homens pesquisadores são tão ativos quanto as mulheres, respondendo por quase a metade das publicações, com expressiva participação das Ciências Humanas (41\% do total dos estudos sem base empírica). O cenário se modifica quando se analisam apenas os estudos de base empírica: há $66 \%$ de autoras mulheres - 75\% delas são oriundas das Ciências da Saúde e 14\%, das Ciências Humanas.

\section{Estudos de base empírica}

As pesquisas com base empírica foram majoritariamente conduzidas por pesquisadores com garantia de sigilo no ato profissional, a saber, médicos e enfermeiras. Foram estudos conduzidos em serviços de saúde e/ou hospitais universitários, o que facilitou a sobreposição entre a figura do pesquisador e a do responsável pela assistência à saúde. Tal sobreposição de papéis foi o que permitiu a realização das primeiras pesquisas com grupos de mulheres que buscavam hospitais públicos para a finalização do aborto. Os profissionais que davam assistência às mulheres eram também os que analisavam suas trajetórias reprodutivas. A proteção à pesquisa se apoiava no respeito ao sigilo e à confidencialidade, dois valores centrais aos serviços de atenção à saúde. Esta se manteve como a principal característica da pesquisa sobre aborto nos anos 1990 no Brasil.

Nesse período, houve uma concentração dos estudos empíricos sobre o perfil das mulheres que realizam aborto no Brasil. Grande parte deles adotou pelo menos uma das seguintes técnicas de levantamento de dados: informações sobre hospitalizações em bases do Ministério da Saúde; busca ativa de mulheres internadas em processo de abortamento para procedimentos médicos; análise de prontuários e outros documentos hospitalares; e entrevistas à beira do leito ou no domicílio. Os estudos reconhecem o desafio ético envolvido nas pesquisas sobre aborto, pois é entre a promessa de sigilo e o risco de uma denúncia que os dados são coletados. Essa tênue fronteira é uma possível explicação para a prevalência das pesquisas em campos disciplinares com garantia de sigilo profissional (Medicina e Enfermagem) e para a concentração de $30 \%$ do total dos estudos de base empírica em um universo de 15 pesquisadores pertencentes a universidades públicas ou vinculados a serviços de assistência em hospitais universitários.

A vasta maioria dos estudos empíricos foi realizada na Região Sudeste (75\%), havendo uma concentração no Estado de São Paulo (58\% do total). Os pesquisadores responsáveis pelos es- 
tudos estão sediados em universidades públicas (88\% do total). Dado semelhante é encontrado na plataforma de grupos de pesquisa do Conselho Nacional de Desenvolvimento Científico e Tecnológico (CNPq), que não indica nenhum grupo de pesquisa com a palavra-chave "aborto" em universidades confessionais no país. As organizações não governamentais são responsáveis por $9 \%$ do total de pesquisas com base empírica durante o período analisado.

Os estudos de base populacional foram majoritariamente conduzidos em hospitais públicos e universitários localizados em capitais, havendo uma concentração nos estados da Bahia, Ceará, Pernambuco, Rio de Janeiro, Rio Grande do Sul e São Paulo. Do ponto de vista da distribuição regional, não há estudos de base empírica sobre a Região Norte; além disso, apenas $14 \%$ do total de estudos foram realizados sobre o Nordeste, e $4 \%$ sobre o Centro-Oeste. Em geral, as pesquisas se baseiam em observações coletadas em um período igual ou superior a 12 meses. Os dados dos estudos têm origem em levantamentos documentais; amostras aleatórias e não aleatórias de mulheres; inquéritos de caráter censitário; e compilações dos dados do Sistema de Informações Hospitalares do Sistema Único de Saúde. As técnicas de pesquisa documental e entrevistas são as mais utilizadas, tendo sido adotadas em mais de $70 \%$ dos estudos de base empírica.

A maioria das publicações são versões abreviadas de pesquisas acadêmicas para titulação, em especial dissertações de mestrado e teses de doutorado em Saúde Pública, que correspondem a $24 \%$ do total de estudos de base empírica. Os estudos em hospitais e/ou clínicas privadas não alcançam $2 \%$ do total de pesquisas com base empírica. Em geral, referem-se aos temas do aborto espontâneo ou recorrente e de novas tecnologias reprodutivas. Não há estudos sobre o aborto in- duzido e o universo da assistência privada à saúde no Brasil.

\section{Desafios éticos}

Foi com a implementação do sistema nacional de avaliação da ética em pesquisa - Sistema Comitê de Ética em Pesquisa/Comissão Nacional de Ética em Pesquisa (CEP/CONEP) - que a reflexão sobre ética, pesquisa e aborto ascendeu ao patamar de questão prioritária à agenda científica, em meados dos anos 1990. As pesquisas dos anos 2000 foram majoritariamente avaliadas pelo Sistema CEP/CONEP, e os autores reservaram espaços significativos da argumentação para descrever os cuidados e desafios éticos da coleta de dados.

A importância de descortinar o cenário de restrições legais e as estratégias éticas para a pesquisa sobre aborto é que os resultados de pesquisa refletem o que foi possível conhecer no Brasil nos últimos vinte anos. As metodologias adotadas partem do cenário legal restritivo a que estão submetidos os pesquisadores. Por isso, grande parte das pesquisas foi realizada em hospitais universitários e públicos localizados em centros urbanos e procurou prioritariamente responder a questões relacionadas à assistência à saúde. A agenda de pesquisa sobre aborto foi grandemente definida pelas urgências da assistência - por isso a morbimortalidade materna relacionada ao aborto induzido esteve em pauta durante duas décadas -, mas também pelos cenários possíveis de coleta dos dados. Sair dos hospitais e se aproximar do espaço doméstico, dos saberes femininos e tradicionais, da participação dos homens na decisão pelo aborto são alguns dos novos itinerários que ampliarão a pesquisa sobre aborto e saúde pública no Brasil. 


\section{Resumo}

O objetivo deste artigo é apresentar as principais características do campo de pesquisas sobre aborto no Brasil entre 1987 e 2007. Foram pesquisadas 88 bases bibliográficas de dados e recuperadas 2.109 fontes de informação. Os resultados mostram que o campo de estudos sobre aborto é dominado por mulheres pesquisadoras, sediadas em universidades públicas e organizações não governamentais da Região Sudeste, com formação em Ciências da Saúde. Não há pesquisas sobre o aborto na Região Norte; $14 \%$ das pesquisas foram realizadas sobre o Nordeste, e 4\% sobre o Centro-Oeste. O tema do aborto se manteve ativo na comunicação científica no período pesquisado, havendo um crescimento em meados dos anos 2000.

Aborto; Pesquisa Empírica; Mulheres

\section{Colaboradores}

As quatro autoras foram responsáveis pela redação da nota de pesquisa.

\section{Agradecimentos}

A pesquisa Aborto e Saúde Pública foi financiada pela Organização Pan-Americana da Saúde/Organização Mundial da Saúde por meio do Termo de Cooperação e Assistência Técnica ao Ajuste Complementar (BR/ CNT/07/00467.001).

Recebido em 01/Set/2008

Versão final reapresentada em 02/Dez/2008 Aprovado em 13/Fev/2009 